\title{
ČUDESNE ŽENE NA RUBU VREMENA: (RADIKALNE) FEMINISTIČKE UTOPIJE*
}

U radu se istražuju veze između utopijske književnosti i (radikalnih) feminističkih ideja, te je, stoga, dat i jezgrovit istorijski prikaz razvoja ženskog pitanja u okviru utopijskog žanra, sa posebnim osvrtom na značaj mita o Amazonkama kao pripadnicama sveženske zajednice. Tokom istraživanja primenjen je interdisciplinarni pristup jer se i utopijske i feminističke ideje javljaju ne samo u književnosti već i u različitim naukama i medijima, poput filozofije, stripa, televizije i filma.

Ključne reči: Amazonke, Čudesna žena (Wonder Woman), feminizam, naučna fantastika, utopija.

Utopija je, prema Sardžentu, društveni san (SARGENT 1994: 3), a kako primećuje Snodgras, „svetovi snova prirodni su deo feminističke literature” jer feminističke utopije ženama nude „spas u carstvima nesputanim seksizmom i mizoginijom prošlosti i sadašnjosti” (SNodgrass 2006: 200). Reč utopija, koju je skovao Tomas Mor, označava, od njegovog doba pa sve do danas, imaginarno savršeno društvo. Ipak, i pored Morovih napora da svoju Utopiju prikaže kao idealnu zajednicu u potpunosti ostvarene jednakosti, prikazano društvo u suštini je duboko patrijarhalno, a žene su i dalje potčinjene muškarcima. Kako ističe Buker, „to što Mor nije bio u stanju da zamisli društvo

Rad je nastao u okviru projekta „Srpska književnost u evropskom kulturnom prostoru". 
u kome su žene zaista ravnopravne s muškarcima podseća nas na to koliko su duboko ukorenjene rodne predrasude na Zapadu" (BookeR 1994).

Iako je ceo književni žanr nazvan upravo po Morovoj Utopiji, ipak, nije to bilo prvo delo te vrste u svetu. Povrh svega, u nekima koja su nastala znatno ranije i koja su, pri tom, potekla iz pera muškarca, nailazimo na radikalno drugačiji pogled na položaj i ulogu žene u društvu. Najraniji takav primer možemo naći još u antičko doba - u Aristofanovim komedijama iz četvrtog i petog veka pre nove ere, kao što su, primerice, Lizistrata, Tesmoforijazuse i Eklesijazuse. Premda su u pitanju satirične utopije, značajno je da su to književna dela u kojima žene preuzimaju vlast i uvode nove društvene norme i pravila, pa tako, npr. ukidaju privatno vlasništvo, sprečavaju rat, ili kažnjavaju znamenitog tragičara Euripida zbog toga što je u svojim tragedijama ocrnio žene. Ako pomenute društvene 'novotarije' i nisu prikazane kao pozitivan ideal ka kome atinsko društvo treba da teži, ove komedije, ipak, na sasvim subverzivan način, kritikuju postojeće stanje i pružaju pogled na alternativne društvene modele, radikalno drugačije od postojećih. Tako, na primer, atinske žene u komediji Eklesijazuse uvode protokomunistička rešenja:
... biće to takva država
Da će novac, i zemlja, i druga blaga sva,
Što svako ima, bit' slobodna i opšta,
Zajednička za sve; a od toga zaista,
K’o domaćine prave, hranićemo vas, izdržavati,
Vama udeljujuć', i o vama brinuti.
(ARISTOFAN 1947: 555) ${ }^{1}$

Ako je Aristofan i bio zajedljiv prema ženama, tako nešto se zasigurno ne može tvrditi za Platona, koji u Državi, svom najpoznatijem delu i ujedno najznačajnijoj antičkoj utopiji, ,pokazuje veliku originalnost i, donekle, značajan stepen modernosti” (BRISSON 2012) jer se otvoreno zalaže za jednakost polova:

1 Prevod preuzet iz Đergović-JoKsIMović 2009: 41. 
Nema [...] nikakvog posla u upravi države koji bi pripadao ženi zato što je žena, niti muškarcu zato što je muškarac, nego su prirodne sposobnosti podjednako podeljene među oba stvorenja, i u svima poslovima može po svojoj prirodi učestvovati žena, i u svima poslovima muškarac, samo je žena u svima slabija od muškarca. (Platon 2002: 143)

Štaviše, ne samo da pripadnice sloja čuvara u Platonovoj Državi dobijaju jednako obrazovanje kao i muškarci već mogu postati i vladarke (Platon 2002: 235). ${ }^{2}$ A da u Platonovom slučaju nije u pitanju prolazna ekscentričnost, svedoči i činjenica da on i u svom delu Zakoni ponovo ističe da dečaci i devojčice treba da dobiju jednako obrazovanje. Tom prilikom Platon se osvrće na mit o Amazonkama, ratnicama koje žive u svojevrsnoj ženskoj utopijskoj zajednici, očito želeći da ovaj mit upotrebi kao dokaz o realnoj mogućnosti i opravdanosti emancipacije žena.

Inače, u Platonovo vreme Amazonke su već činile značajan segment grčke kulture - javljaju se, na primer, u Heraklovim zadacima, a pominju ih i Homer u Ilijadi, i Eshil u Okovanom Prometeju, ali i Herodot u svojoj Istoriji:

kad su Heleni ratovali s Amazonkama (Skiti nazivaju Amazonke „Oiorpata”, što na helenskom jeziku znači „mužoubica”, jer „oior” znači čovek, a „pata” znači ubiti), tada su [...] posle pobede kod Termodonta Heleni otplovili na tri lade s onim Amazonkama koje su uspeli da zarobe, a ove su na pučini napale na muškarce i sve ih poubijale. One nisu znale za brodove niti su umele da rukuju krmama, jedrima ni veslima, nego su [...] pustile da ih nosi vetar i talasi, pa su tako dospele do grada Kremna u Meotskom jezeru. Ovaj grad nalazi se u zemlji slobodnih Skita. Tu su se Amazonke iskrcale sa lađa i krstarile po okolnim predelima. (Herodot u Gavela 1988: 149)

Nakon toga, po Herodotu, Amazonke su stupile u kontakt sa skitskim muškarcima koji su uspeli da ih zavedu i ožene se njima. Ipak, kako Amazonke nisu mogle da prihvate skitske običaje, ubedile su svoje muževe da se s njima presele na novu lokaciju, gde su mogle da zadrže

2 Valja imati na umu da Platon nije svim slojevima žena dodelio rodnu ravnopravnost, te tako njegovi pogledi na položaj žena izazivaju podeljene reakcije. Usled toga jedni ga danas smatraju protofeministom, a drugi antifeministom (više o tome u Tuana 1994). 
i s kolena na koleno prenose svoje amazonske običaje, koji su, između ostalog, podrazumevali i rodnu jednakost. Kako ističe Herodot, tako je nastao narod Sauromata. Sve do nedavno, ovom Herodotovom predanju nije pridavan veliki značaj jer za njega nije bilo materijalnih potvrda, a Amazonke su tradicionalno prikazivane u skladu s predanjem kao mitske ratnice koje su živele u sveženskoj zajednici, čija se lokacija najčešće vezuje za Temiskiru, grad na reci Termodont. Nedavna arheološka istraživanja potvrdila su pretpostavke da su u drevna vremena na teritoriji nekadašnje Skitije zaista postojale žene ratnice (više o tome u MaYor 2014). Da li one imaju veze s Amazonkama ne može se, zasad, pouzdano znati.

Tomas Mor je za svoje vreme bio izuzetno obrazovan i dobro je poznavao ne samo starogrčki već i dela pisana na tom jeziku. Posebno je cenio Platona i toliko bio oduševljen njegovom Državom da u nekoliko navrata apostrofira ovo delo u Utopiji, ulazeći pri tom u otvoreni interutopijski dijalog s njim. On, ipak, nije u potpunosti preuzeo Platonove slobodoumne ideje o rodnoj ravnopravnosti već se zadržao samo na tome da žene imaju pravo na obrazovanje kao i muškarci, te da mogu da obavljaju svešteničke dužnosti. Indikativno je da, nalik mitskim Amazonkama, i stanovnice Utopije imaju obavezu vojne obuke i učešća u ratu. U svemu ostalom, međutim, potčinjene su muškarcima i, naravno, nema ni reči da bi u tom društvu žene mogle postati vladarke. Svakako, Morova rešenja moramo sagledati u istorijskom kontekstu. Naime, čak i Kristina de Pizan, i zvanično „prva feministička filozofkinja" (BuRKETT) i pisac prve feminističke utopije pod nazivom Grad žena (1405), okosnicu borbe za prava žena temelji na njihovom pravu na obrazovanje, a, kako predviđa, u njenom Gradu žena živeće „samo obrazovane i ugledne žene, jer će zidine našeg grada biti zatvorene za sve one koje nemaju vrlina” (De PIZAN 2003: 14). Značajno je da i Kristina de Pizan veliki prostor posvećuje upravo istoriji društva Amazonki, čije su vladarke bile učene žene:

Istorija te uči da su osnivanje kraljevstva Amazonije nekada pokrenule brojne, veoma hrabre žene koje su prezirale ropski položaj. Održavale su ga dugo i njime su vladale različite kraljice jedna za drugom: birale su veoma 
učene gospe koje su vladale mudro čuvajući državu u svoj njenoj moći.

(De PiZAN 2003: 16)

Nakon toga uslediće prikaz celokupne istorije Amazonki (De PizAN 2003: 39-48), a potom i drugih značajnih manje ili više obrazovanih žena koje u toj alegoriji grade simboličan Grad žena, što je, zapravo, autorkina knjiga. Nažalost, i u najprosvećenijim zemljama Zapadne Evrope petnaestog veka, poput Francuske, gde je De Pizan živela i stvarala, pravo na obrazovanje bilo je muški zabran, a da ne govorimo o drugim aspektima rodne ravnopravnosti. Otud i ne čudi previše podatak da sve do devetnaestog veka među piscima utopija ima veoma malo žena. Zapravo, između prve poznate utopije koju je na engleskom jeziku napisala žena - romana Bleštavi svet (1666) Margaret Kavendiš $\breve{s}^{3}$ - i naredne, Opis imanja Milenijum i okoliša $a^{4}$ (1762) Sare Skot, prošlo je bezmalo stotinu godina. U međuvremenu je Meri Astel 1694. godine objavila pamflet Ozbiljan predlog ženama za unapredenje njihovog pravog i najvećeg interesa, u kome se zalaže za formiranje ženskih obrazovnih institucija nalik svetovnim manastirima (SARGENT). Kako ukazuju Danavert i Kolmerten, „uzor tih ranih ženskih začudnih književnih dela nije ser Tomas Mor [...] već, umesto toga, feministički modeli obrazovanja žena: manastir, salon, seosko imanje sa velikom bibliotekom" (DONAWERTH 1994: 6).

Kad je reč o Amazonkama i prikazu njihove zajednice, mora se reći da se u engleskoj književnosti one javljaju dosta rano i relativno često i to kod nekih od najznačajnijih pisaca: počevši od „Vitezove priče” iz Čoserovih Kanterberijskih priča (1387-1400), gde se pominje Tezejeva ženidba Hipolitom, kraljicom Amazonki, preko Vilinske kraljice (1596) Edmunda Spensera, gde je u petoj knjizi opisana amazonska kraljica Radigunda, pa do Šekspirovog Sna letnje noći (1595/6), u kome

3 U delu je prikazano fantastično utopijsko kraljevstvo kojim vlada žena. Kavendiš je napisala i jednu utopijsku dramu, Manastir zadovoljstva (1668), o sveženskoj zajednici (SARGENT).

4 Imanjem Milenijum upravljaju učene žene koje žive u celibatu (SARGENT). 
se radnja odvija u noći uoči Tezejevog i Hipolitinog venčanja. ${ }^{5}$ Ipak, u retkim književnim delima u kojima su same Amazonke glavna tema, reč je prevashodno o satirama u kojima je njihovo društvo izvrgnuto ruglu. Simptomatično je da su autori takvih dela uglavnom muškarci. ${ }^{6}$ Kako primećuje Nusbaum, „strašno žensko čudovište, Amazonka [...] proganjaće maštu muškaraca tokom celog osamnaestog veka i dalje” (Nussbaum 1984: 5̋6).

Zanimljivo je da će početkom devetnaestog veka žensko pitanje postati centralno u istupanjima socijaliste utopiste Šarla Furijea, kome se neretko u zasluge upisuje i to da je prvi upotrebio termin feminizam. ${ }^{7}$ Kako god, ostaće zabeleženo da je utopista Furije nadahnuo mnoge potonje feministkinje svojom konstatacijom:

Društveninapredaki istorijskepromene dogadaju se kao rezultat napredovanja žena ka slobodi, a do dekadencije društvenog poretka dolazi usled smanjenja sloboda žena. [...] Proširenje ženskih privilegija opšte je načelo za postizanje celokupnog društvenog napretka. (FourRier u SMaLdone 2014: 36)

Utopije sa feminističkim idejama doživeće prvi masovniji uzlet upravo u devetnaestom veku, kada na Zapadu jača borba za ženska prava, uključujući i pravo glasa. Tada je i Amerika dobila svoju prvu utopiju iz pera jedne autorke. Bio je to roman Trista godina od sada (1836) Meri Grifit, u kome se junakinja budi u dalekoj budućnosti, u kojoj su ženama zagarantovana ekonomska prava. „Tokom osamdeset tri godine, od 1836. do 1919, američke književnice izvršile su značajne prepade na žanr utopijske književnosti u kome su dominirali muškarci, krčeći

5 Mit o Amazonkama obrađivan je i u drugim evropskim književnostima: u italijanskoj, npr. u Bokačovom spevu Tezeida (oko 1340); u španskoj, npr. u viteškom romanu Esplandijanove pustolovine (1510) De Montalva; u nemačkoj, npr. u Fon Klajstovoj drami Pentesileja (1808) (više o tome u MaGeE 1996). U srpskoj književnosti Amazonke se pominju u Romanu o Aleksandru Velikom iz 14. veka (MARINKOVIĆ 1986: 142-143).

6 Jedan od najranijih primera je Svet drugačiji i isti (1605) Džozefa Hola, u kome je prikazana i Amazonija (SARGENT). U srpskoj književnosti satiričan pristup ženskom pitanju nalazimo u priči „U XXI veku” (1895) Svetolika Rankovića.

7 Termin se javio početkom devetnaestog veka u Francuskoj, ali su francuski rečnici pogrešno pripisali njegovo poreklo Furijeu (OfFEn 2006: 356). 
put velikanima tog žanra u poznom dvadesetom veku”, ističe Snodgras (SNODGRASS 2006: 200). Zapravo, u tom kratkom periodu nastalo je više ženskih utopija nego u svim prethodnim vekovima zajedno. Po svojoj osobenosti i smelosti ideja izdvaja se Mizora (1880/81) Meri E. Bredli Lejn, utopija o sveženskom naprednom tehnološkom društvu u unutrašnjosti zemlje, gde se žene razmnožavaju partenogenezom. Neobičan spoj mita o Amazonkama, feminizma i socijalističkih ideja pojavio se s druge strane Atlantika, u delu Nova Amazonija (1889) Elizabet Burgojn Korbet, u kome je Irska budućnosti prikazana kao svojevrsna futuristička zajednica „Amazonki”, natprirodno visokih, mladolikih i dugovečnih žena koje upravljaju državom dok je muškarcima eksplicitno zabranjeno da obavljaju javne dužnosti (SARGENT).

I Ilejn Šovolter primećuje da su „u engleskoj i američkoj književnosti književnice [...] često zamišljale amazonske utopije, gradove ili zemlje smeštene u zoni divljine ili na njenoj granici” (SHOWALter 201). Početak dvadesetog veka obeležen je pojavom upravo takvog dela. Američka književnica Šarlota Perkins Gilman u romanu Njena zemlja $(1915)^{8}$ predočava svoju verziju amazonske utopije. I u toj „neotkrivenoj zemlji strogo amazonske prirode" (Perkins Gilman 2016), bez nasilja i dominacije, značajna uloga pripisuje se obrazovanju, a kao i u Mizori, njene stanovnice razmnožavaju se pomoću partenogeneze. Inače, Perkins Gilman je objavila ukupno dvanaest dela utopijskog žanra (SARGENT), što je svrstava među najplodonosnije utopijske autorke toga doba. Ipak, skoro sva su objavljena u njenom časopisu $\mathrm{Fo}^{-}$ rerunner, bez velikog odjeka, a roman Njena zemlja pojavio se u formi knjige prvi put tek 1979. godine.

Snažnije prisustvo mita o amazonskoj ženskoj utopiji, kao i njegovo dalje širenje u popularnoj kulturi, omogućila je pojava novih medija: najpre filma, potom i stripa, a zatim i televizije. Mora se, međutim, istaći da je u okviru filmske umetnosti zaokružen proces konačne vizuelno-ideološke stereotipizacije Amazonki. One će postati prepoznatljivo kostimizirane egzotične i okrutne ratnice; njihov ogoljeni i

8 Reč je o drugom delu trilogije koju čine i romani Pokrenuti planinu (1911) i Sa njom u našoj zemlji (1916). 
naglašeni seksepil biće zakonomerno dopunjen odsustvom emocija ili prezirom prema muškarcima. Podaci o njihovoj alternativnoj radikalnoj utopijskoj zajednici biće marginalizovani, tj. svedeni na puke geografske podatke o egzotičnoj lokaciji koja varira od džungli Amazonije $^{9}$ do afričkih šuma. Prve naznake i najave filmske fascinacije egzotičnim moćnim ženama možemo pronaći u mnogobrojnim ranim filmskim adaptacijama romana Ona (1887) Rajdera Hagarda. Godine 1945. snimljen je film Tarzan $i$ Amazonke, a samo dve godine kasnije i Kraljica Amazonki. ${ }^{10}$

Ipak, najspektakularniji događaj odigrao se na stranicama stripa. Već krajem 1941. godine (i samo tri godine posle rođenja Supermena) u rat protiv nacista krenula je i punokrvna amazonska junakinja i prva slavna superjunakinja ${ }^{11}$ - Čudesna žena (Wonder Woman), tj. princeza Dijana sa Temiskire, ${ }^{12}$ kći amazonske kraljice Hipolite. Čudesna Žena nije se nimalo uklapala u stereotip o agresivnim ratnicama Amazonkama. Naprotiv, „ona je odrasla u najidiličnijem predelu na zemlji i postala junakinja koja pomaže drugima i koja širi amazonske vrednosti” (HANLEY 2014: 20). Njen tvorac, kontroverzni psiholog Vilijam Moulton Marston, nije krio svoje subverzivne namere i javno je govorio o potrebi stvaranja novog i drugačijeg uzora namenjenog devojčicama modernog doba. Povrh svega, njegova junakinja trebalo je da pripremi čitaoce za veliku neizbežnu revoluciju - dolazak matrijarhata (HaNLEY 2014: 16). Malo je poznato da su uz strip Čudesna žena objavljivani i dodaci pod nazivom Čudesne žene kroz istoriju, u kojima su prikazana dostignuća pedeset sedam znamenitih žena (HANLEY 2014: 18). Rajsko ostrvo Amazonki trebalo je da posluži kao dokaz i potvrda nadmo-

9 I sam naziv Amazonije svedoči o rasprostranjenosti mita o Amazonkama (više o tome u MageE 1996).

10 Amazonke su se, pod originalnim ili nekim drugim imenom, pojavljivale i u mnogobrojnim potonjim filmovima u manje-više sličnoj ulozi.

${ }^{11} \mathrm{U}$ istoriji stripa postojale su superjunakinje i pre Čudesne žene, ali nijedna nije postigla takav uspeh kao ona (više o tome u HANLEY 2014).

12 U prvim brojevima stripa ostrvo se zvalo Rajsko ostrvo, da bi tek kasnije dobilo naziv Temiskira. 
ći jedne prave ženske utopijske zajednice. Otud ne čudi što kraljica Hipolita samouvereno tvrdi da na amazonskom plodnom ostrvu čudesne vegetacije „nema oskudice, nema bolesti, nema mržnje, nema ratova. [...] Zato smo mi Amazonke uspele da nadaleko nadmašimo izume takozvane muške civilizacije. Ne samo da smo jače i mudrije od muškaraca - već je i naše oružje bolje - a naše letelice su naprednije!" (HANLEY 2014: 19).

Čudesna žena, svakako, spada u red najdugovečnijih i najznačajnijih naučnofantastičnih superjunaka i superjunakinja. Njeno pojavljivanje bilo je revolucionarno čak i ako ga sagledamo u kontekstu naučne fantastike koja je, čini se, u svojim liberalnim shvatanjima uvek bila bar jedan korak ispred ostatka društva. Zapravo, iako se naučnoj fantastici danas odaje priznanje kao žanru koji može da nas oslobodi od okova predrasuda i stereotipa (CLuTE), na samim počecima i tokom većeg dela tzv. zlatnog doba naučne fantastike nije bilo tako, a naročito u pogledu likova žena, najčešće svedenih na stereotipe i klišee. U tom smislu, Čudesna žena označava ranu najavu onoga što će se u naučnoj fantastici i utopiji odigrati tek nekoliko decenija kasnije. Otud ne čudi odluka da 1972. godine na naslovnoj strani prvog broja feminističkog časopisa Ms. bude niko drugi do Čudesna žena (HANLEY 2014: x). Ne zaboravimo da ova junakinja nije propuštala priliku da se sa stranica stripa direktno obrati svojim čitateljkama podstičući ih da se emancipuju i bore za svoja prava.

Kada je reč o radikalnim ženskim utopijama, do najvećeg preokreta došlo je upravo kasnih šezdesetih i ranih sedamdesetih godina dvadesetog veka. Kako se ističe u Enciklopediji naučne fantastike, jedan od najznačajnijih doprinosa feminističke naučne fantastike iz tog perioda ogleda se u tome što je

postavljala pitanja šta se može drugačije uraditi [...] Feministkinjama je naučna fantastika pužila mogućnost da dovedu u pitanje ideju o ženama kao „drugome” u odnosu na muškarce i da sprovedu ono što Le Gvin naziva „misaonim eksperimentima” o tome kako se na drugačiji način može strukturisati polni poredak. (CLUTE) 
Među autorkama koje su svojim delima snažno prodrmale rodnu učmalost u svetu naučne fantastike izdvajaju se, svakako, Ursula le Gvin, Mardž Pirsi, Džoana Ras, Suzi Maki Carnas i Oktavija Batler. Premda mnogi romani ovih autorki zaslužuju našu pažnju, Žena na rubu vremena (1976) Mardž Pirsi ne samo da je radikalna feministička utopija u kojoj autorka jednako uspešno preispituje pitanja obrazovanja, rase i klase zalažući se za korenite društvene promene, već i delo koje uspostavlja čvrste veze, kako sa feminističkim pokretom tako i sa teorijom, tj. kritikom. „I odista, roman Pirsi, u kome je buduća feministička utopija Metapoiset isprepletana sa distopijskom pričom o psihijatrijskoj pacijentkinji Koni Ramos, postao je svojevrsno Sveto pismo za ženski pokret u Sjedinjenim Državama” (DonawerTh 1994: 11). Indikativno je i da s pojavom drugog talasa feminizma tropi karakterisitčni za naučnu fantastiku postaju dominantno obeležje i jednog dela teorijskog feminističkog diskursa. U tom smislu, delo Dijalektika pola (1970) jedne od najradikalnijih i najkontroverznijih feministkinja, Šulamit Fajerston, doslovno najavljuje neka od obeležja futurističke zajednice iz romana Žena na rubu vremena:

Reprodukcija vrsta koju obavlja jedan pol a na korist oba biće zamenjena (makar postojanjem te opcije) veštačkom reprodukcijom: oba pola rađaće decu, ili nezavisno jedan od drugog, kako ko želi to da posmatra; zavisnost deteta od majke (i obrnuto) ustuknuće pred mnogo kraćom zavisnošću od male grupe drugih ljudi [...] Podela rada biće okončana potpunim ukidanjem rada (pomoću kibernetike). (Firestone 1971: 12)

Feministički utopijski roman Mardž Pirsi pozicioniran je, zapravo, na vremenskoj sredokraći između dva jednako značajna feministička teksta - onog Šulamit Fajerston i „Manifesta kiborga” (1984) Done Haravej. Ne samo da oba koriste trope naučne fantastike već na originalan i radikalan način promišljaju žensko pitanje. Mada zapaža da su „čudovišta oduvek definisala granice zajednice u Zapadnoj imaginaciji”, te da su „kentauri i Amazonke drevne Grčke postavili granice centralizovanog polisa grčkog muškarca svojim ukidanjem braka i zagraničnom kontaminacijom ratnika elementima životinje i žene", Haravej ističe da kiborzi „u feminističkoj naučnoj fantastici definišu 
sasvim drugačije političke mogućnosti i granice u odnosu na one koje predlaže uobičajena književnost Muškaraca i Žena” (HaRAwAY 2001: $315)$.

I premda se „Manifest kiborga” Done Haravej okončava eksplicitnom izjavom „radije bih bila kiborg nego boginja” (HARAWAY 2001: 316), svedoci smo da na filmu i u popularnoj kulturi ovih dana primat preuzima upravo jedna (polu)boginja koja je nedavno doživela pravo društveno i medijsko uskrsnuće. Reč je, naravno, o Čudesnoj ženi, odnosno o prvom filmu u celosti posvećenom ovoj superjunakinji. Priča o amazonskoj princezi Dijani sa Temiskire do sada je više puta ekranizovana ${ }^{13}$ ali nijedna ekranizacija nije doživela takvu slavu niti privukla toliku pažnju kao ova najnovija. Nažalost, iako filmska priča gotovo u potpunosti prati postavke iz originalnog stripa, ${ }^{14}$ čini se da je oštrica njene društvene kritike u međuvremenu otupela. Filmska Temiskira svedena je na egzotični rajski predeo u kome Amazonke predano uvežbavaju spektakularne borilačke veštine, a Dijanin kulturni šok pri susretu sa našim svetom dočaran je humorističkim scenama u butiku, u kojima se ona čudi tekućoj ženskoj modi (npr. pita da li su korseti vrsta oklopa, te kako se žene bore u tako dugim suknjama...). Ekonomsku, pravnu ili političku obespravljenost žena ili čitavih naroda i država ova superjunakinja neće naći za shodno da prokomentariše. Shodno tome, uzrok Prvog svetskog rata je nekakvo metafizičko zlo koje tinja u nesavršenim ljudima uz malu pomoć boga rata Aresa, a o ekonomskim, političkim, geopolitičkim i inim uzrocima, naravno, nema ni reči. Društvo spektakla dobilo je superjunakinju baš kakvu zaslužuje - ona se možda može nositi s bogovima, ali i ne pomišlja da izađe na kraj s ljudskim slabostima. Time je njena uloga istrgnuta iz sfere feminističke naučne fantastike i gurnuta još snažnije u naručje puke fantastike. S druge strane, svedoci smo da se u naučnoj fantastici

${ }^{13}$ Do sad je o ovoj junakinji snimljen jedan TV film (1974), TV serija (emitovana u periodu 1975-1979) i jedan animirani dugometražni fim (2009). Osim toga, pojavljivala se u sporednoj ulozi u više animiranih filmova (ali i u igranom filmu Betmen protiv Supermena, 2016 ) i video igara.

${ }^{14}$ Medu najkrupnijim razlikama jeste odluka da radnja bude smeštena u doba $\mathrm{Pr}$ vog a ne Drugog svetskog rata. 
uveliko javljaju novi i originalni ženski glasovi (oličeni, na primer, u Nalo Hopkinson, En Leki ili Kameron Harli), a pravi procvat doživljava ženska omladinska naučna fantastika predvođena autorkama poput Suzan Kolins i Veronike Rot, čija dela o mladim buntovnicama prikazuju neke drugačije Amazonke.

Kao što smo mogli da se uverimo, u potrazi za rešenjem postojeće rodne neravnopravnosti, kroz istoriju su se utopija i feminističke ideje neretko ukrštale. Obrazovanje žena i osnivanje učenih ženskih zajednica jedni su od najranijih feminističkih utopijskih motiva. Gotovo istovremeno iz antičke grčke kulture preuzet je i mit o amazonskoj sveženskoj zajednici. Rezultati tih prepletaja nisu uvek bili ni uspešni ni svima dragi. Ipak, svim tim iskoracima zajednička je ogromna hrabrost njihovih autorki, tih usamljenih čudesnih žena pozicioniranih na rubu vremena i zagledanih u neku drugačiju budućnost.

\section{IZVORI I CITIRANA LITERATURA}

Aristofan. Komedije, prev. Koloman Rac. Zagreb: Matica hrvatska, $194 \%$.

BоoKer, M. Keith. "Woman on the Edge of a Genre: The Feminist Dystopias of Marge Piercy". Science Fiction Studies 64/21 (1994). http://www.depauw.edu/sfs/backissues/64/booker.htm

Brisson, Luc. "Women in Plato's Republic". Études platoniciennes 9 (2012). http://etudesplatoniciennes.revues.org/277

BurketT, Elinor and Laura Brunell. "Feminism". Encyclopaedia Britannica. https://www.britannica.com/topic/feminism\#ref721979

Clute, John et al. (ed.). The Encyclopedia of Science Fiction. http://sf-encyclopedia.com/category/all

De Pizan, Kristina. Grad žena, prev. Suzana Pavlov. Beograd: Feministička 94, 2003.

DonawerTh, Jane L. i Carol A. Kolmerten (ed.). Utopian and Science Fiction by Women: Worlds of Difference. New York: Syracuse University Press, 1994.

Đergović Joksimović, Zorica. Utopija: Alternativna istorija. Beograd: Geopoetika, 2009.

Firestone, Shulamith. The Dialectic of Sex. London: Jonathan Cape Ltd, 1971. 
Fourier, Charles, Document 2.4. "Degradation of Women in Civilization. William Smaldone" (ed.). European Socialism: A Concise History with Documents. Lanham: Rowman \& Littlefield Publishers, Inc, 2014.

Gavela, dr Branko (ur.). Antička književnost: Herodotova istorija I i II, prev. Milan Arsenić. Novi Sad: Matica srpska, 1988.

Gilman, Charlotte Perkins Stetson. Herland. https://www.gutenberg.org/ files/32/32-h/32-h.htm

Hanley, Tim. Wonder Woman Unbound: The Curious History of the World's Most Famous Heroine. Chicago: Chicago Review Press Incorporated, 2014.

Haraway, Dona. "A Cyborg Manifesto: Science, technology and socialist-feminism in the late twentieth century". David Bell and Barbara M. Kennedy (eds.). The Cybercultures Reader. London and New York: Routledge, 2001.

Magee, Bruce Robert. "The Amazon Myth in Western Literature". LSU Historical Dissertations and Theses, 1996. http://digitalcommons.lsu. edu/gradschool_disstheses/6262

Mayor, Adrienne. The Amazons: Lives and Legends of Warrior Women Across the Ancient World. Princeton University Press, 2014.

Mor, Tomas. Utopija, prev. Franjo Barišić. Beograd: Utopija, 2002.

Nussbaum, Felicity A. The Brink of All We Hate: English Satires on Women, 1660-1750. Lexington: The University Press of Kentucky, 1984.

Offen, Karen. Feminism. Peter N. Stearns (ed.). Encyclopedia of Social History. New York \& London: Garland Publishing, Inc, 1994, 356-358.

Piercy, Marge. Woman on the Edge of Time. New York: Fawcett Crest, 1991.

Platon. Država, prev. dr Albin Vilhar i dr Branko Pavlović. Beograd: BIGZ, 2002.

SARgENT, Lyman Tower. "The Three Faces of Utopianism Revisited". Utopian Studies. 5/1 (1994): 1-3\%.

SARGENT, Lyman Tower. Utopian Literature in English: An Annotated Bibliography From 1516 to the Present. http://openpublishing.psu.edu/utopia/

ShowaLter, Elaine. "Feminist Criticism in the Wilderness". Critical Inquiry. 8/2 (1981): 179-205.

SNodgrass, Mary Ellen. (ed.). Encyclopedia of Feminist Literature. New York: Facts on File, Inc, 2006.

Tuana, Nancy. (ed.). Feminist Interpretations of Plato. The Pennsylvania State University Press, 1994.

Wonder Woman. Dir. Patty Jenkins. Warner Bros. Pictures. 2017. Film. 
Zorica Đergović-Joksimović

\title{
WONDER WOMEN ON THE EDGE OF TIME: (RADICAL) FEMINIST UTOPIAS
}

\author{
S u m m a r y
}

The paper explores the relationship between utopian literature and (radical) feminist ideas. It provides a brief overview of the development of the feminist issue in the genre of utopia. Special attention is paid to various representations of the myth of the Amazons as members of an all-female community. An interdisciplinary approach is applied since both utopian and feminist ideas appear not only in literature but in different sciences and media, such as philosophy, comics, television and film.

Keywords: Amazons, Wonder Woman, feminism, science fiction, utopia.

Univerzitet u Novom Sadu

Filozofski fakultet

zorica.djergovic.joksimovic@ff.uns.ac.rs 